\title{
Dissections or Prosections; Which Method has a Better Impact on Sustainable Gross Anatomy Knowledge?
}

Manujasri Wimalachandra

University of Colombo

Balasingam Balagobi ( $\sim$ b.balagobi@yahoo.com)

University of Jaffna

Malith Hashintha

National Hospital of Sri Lanka, Hospital Square

Narada Ranasinghe

Colombo North Teaching Hospital

Lamindu Niroshana

National Hospital of Sri Lanka, Hospital Square

Joseph Anthony

University of Colombo

Rohan Jayasekara.

University of Colombo

\section{Research Article}

Keywords: medical education, undergraduate, dissection, prosections.

Posted Date: September 28th, 2021

DOl: https://doi.org/10.21203/rs.3.rs-835505/v1

License: (9) (i) This work is licensed under a Creative Commons Attribution 4.0 International License. Read Full License 


\section{Abstract}

Background: Two groups of medical students in their final year were tested on the key concepts of gross anatomy using a question paper that included true false type questions and identification of anatomical line diagrams. These two batches of students followed a dissection based curriculum and a newly introduced prosections based curriculum at the beginning of their medical education respectively. The prosections based curriculum brought with it a significant cut down on the in-class teaching and learning activities when compared to the old curriculum. The objective of the study was to establish which method was more effective at establishing a core of anatomy knowledge that could be recalled after a considerable amount of time. This would in turn reflect how much of anatomy knowledge one would possess when they start to practice medicine as a newly qualified doctor and also embark on a postgraduate training programme.

Methods: The two groups were subjected without prior warning to a question paper that comprised six questions, each with five True/False statements and four questions on identification and labelling of anatomical line diagrams.

Results: There was no statistically significant difference in the marks obtained for the true false type questions between the two groups $(p=0.076)$, but the prosections group obtained higher marks for the diagram identification questions $(p=0.022)$.

Conclusions: Therefore, it was concluded that a prosection based curriculum when compared to a dissection based curriculum was equally effective at establishing a core of gross anatomy knowledge in a considerably lesser amount of time.

\section{Introduction}

The main goals of teaching anatomy to students in a medical curriculum is to, lay a sound foundation for the learning of further subjects and to inculcate the core concepts of anatomy to carry with them during the rest of their medical careers (Older,2004; Custers,2011). Dissections were the standard method of teaching gross anatomy for centuries but there is a current trend towards the use of prosected specimens as a method of teaching and learning gross anatomy. The pros and cons for each method have been debated by anatomists, surgeons, curriculum developers and students (Nnondim,1990; Jones,1997). Perhaps the reason for this debate stems from the lack of solid evidence to support one method over the other.

The Faculty of Medicine Colombo which was established in 1870 is the second oldest medical school in South Asia. The Department of Anatomy of the, "Colombo Medical School" as it was known then, was one of the first departments that was established in 1913. In the year 1998 the faculty brought about a series of changes to the curriculum in keeping with the major curriculum changes that took place in the United Kingdom in the early nineties (Heylis, 2010). One of the main changes in teaching anatomy was the introduction of prosections to learn gross anatomy in place of cadaver based self dissection. 
An important objective to be achieved in teaching anatomy in the first year of a medical curriculum is to ensure that a significant proportion of core anatomy knowledge is retained with the student when he or she starts to practice medicine as a newly qualified doctor and equally important is how much of anatomy knowledge is retained in a doctor when he or she embarks on a postgraduate training programme to be a surgeon (Gupta, 2007). Therefore, we felt that testing the level of anatomy knowledge four years after their primary anatomy training will give a better indication as to which system of teaching was more effective in achieving the above objectives.

\section{Materials And Methods.}

This study was conducted among two groups of students in their final year at the Faculty of Medicine, University of Colombo, Sri Lanka. These two groups studied gross anatomy using either dissections or prosections. Both these student groups gained admission to the university, on an all island ranking, based on the Z score they obtained in the Advanced level examination. In Sri Lanka, the Advanced level examination functions as the screening examination to choose students for state sector universities. Based on this ranking system, the first 175 to nearly 200 or so students who sat for the advanced level examination from the biological sciences stream (Physics, chemistry and biology) gets selected to the Colombo University.

All methods in this study were performed in accordance with the Declaration of Helsinki. Ethical clearance was obtained from the Ethics Review Committee of Faculty of Medicine, University of Colombo. Informed written consent was obtained from all the participants of this study.

In the dissections group, 8-9 students were allocated to a single cadaver to engage in hands on regional dissection for 3 hours a day 3-4 days of the week. A standard dissection manual was available to the students (Romanes, 2000a; 2000b; 2000c) which was supplemented by a dissection guide prepared by the faculty. Weekly targets were given to students and their progress was randomly supervised by four anatomy demonstrators. Attendance was not mandatory at dissection sessions. In the subsequent batch that followed a prosection based curriculum, student groups of 8-9 were given 3 hours per day on a single day of the week to learn from an assortment of prosected specimens relevant to the week's lesson. Similar to the dissections group they were also supervised by four anatomy demonstrators. The gross anatomy learning was supplemented with lectures, tutorials and self study time in the anatomy museum. A breakdown of the time spent on gross anatomy teaching in the two curricula is shown in Table 1 . Besides the change in gross anatomy learning in the first year, the rest of the medical curriculum remained unchanged till the end of the course in both groups. 
Table 1

Comparison of the time spent on anatomy teaching in the two groups

\begin{tabular}{|lll|}
\hline Learning activity & $\begin{array}{l}\text { Dissection based curriculum - } \\
\text { hours }\end{array}$ & $\begin{array}{l}\text { Prosection based curriculum- } \\
\text { hours }\end{array}$ \\
\hline Lectures & 49 & 56 \\
\hline Dissections/Prosections & 375 & 54 \\
$\begin{array}{l}\text { Small Group Activity and } \\
\text { Tutorials }\end{array}$ & 14 & 10 \\
\hline Total & 438 & 120 \\
\hline
\end{tabular}

In the final academic year of each group, their knowledge on the core concepts of anatomy were tested using a question paper comprising six questions, each with five True/False statements and four questions on identification and labeling of anatomical line diagrams. The questions were designed to cover the main teaching units of their gross anatomy curriculum which were; head and neck, thorax, abdomen, upper limbs and lower limbs. The pretested questionnaire was designed by the authors, who comprised of five junior doctors during their stint as anatomy demonstrators, a consultant surgeon who is also a senior lecturer in anatomy and a senior professor of Anatomy. The question paper was distributed without prior notification and administered in the presence of the authors. Although there was no time limit for the question paper all the students handed over their answers within a period of 30 minutes. Participation in the test was voluntary and had no bearing on their final year grades. The mean scores obtained for the true false type questions were compared using the un-paired $t$ test and the marks for diagram identification were compared using the Mann Whitney $U$ test. The data analysis was done using the software SPSS version 19. Ethics approval for the study protocol was obtained from the Ethics Review Committee of the Faculty of Medicine Colombo, University of Colombo, Sri Lanka.

All questions were designed to test the student's knowledge on the core concepts of anatomy and their application to clinical settings. Two examples of questions are given below,

1. Which of the following statements are true/false?
a. The neurovascular bundle of the intercostals space lies in the lower border of the rib.
b. Right main bronchus is in line with the trachea.
c. The central part of the diaphragmatic pleura is pain insensitive.
d. The right lung has two lobes.
e. The apex of the lung ascends $2.5 \mathrm{~cm}$ above the medial one third of the clavicle.

2. Identify the following structures- A, B, C (Fig. 1)

\section{Results}


A total of 116 students from the 'dissected' group and a total of 92 students from the 'prosected' group volunteered to answer the question paper. Table 2 summarizes the mean scores achieved by each group for true false type questions (marks out of 50), diagram identification (marks out of 50) and total marks. There was no statistically significant difference in the marks obtained for the true false type questions between the two groups. $(p=0.076)$. The prosections group obtained higher marks for the diagram identification questions which was significant at a $p=0.022$

Table 2

-Mean scores achieved by each group for the different components in the question paper

\begin{tabular}{|llll|}
\hline Group & $\begin{array}{l}\text { True false type questions } \\
\text { Mean(+/-SD) }\end{array}$ & $\begin{array}{l}\text { Diagram identification } \\
\text { Mean(+/-SD) }\end{array}$ & Total marks (\%) \\
\hline Prosections & $29.73(+/-8.3)$ & $28.01(+/-6.4)$ & $57.74(+/-12.7)$ \\
\hline Dissections & $28.26(+/-10.1)$ & $26.16(+/-6.9)$ & $54.08(+/-15.1)$ \\
\hline
\end{tabular}

\section{Discussion}

Cadaver based education remains a powerful tool in the gross anatomy learning armamentarium. Visualizing, palpating and discovering the three dimensional relationships of human anatomy cannot be substituted by any other method. Therefore, it is paramount that the time spent around the cadaver is spent in the most effective and productive manner.

In this study we observed that a prosection based curriculum when compared to a dissection based curriculum was equally effective at establishing a core of gross anatomy knowledge that could be recalled after a considerable amount of time. Contrary to expectations the prosected group performed better in the diagram identification part of the assessment. Given the large amount of time spent on dissecting between tissue planes and discovering anatomical landmarks the dissections group was expected to succeed in this segment of the assessment.

Similar observations have also been shared by previous investigators who compared these two learning methods albeit under different circumstances. In a similar study Nonidum(1990) compared the long term retention power of these two methods by testing the student's level of knowledge on the lower limb anatomy four years after it was thought. He concluded prosections were superior to dissections in achieving this objective. In a paper that reviewed the effect of cadaver based self dissection versus other teaching methods in anatomy (Winkelmann, 2007), of the 14 studies reviewed, 12 studies compared dissections to various prosection based teaching methods. Among these 12 studies, the dissected group performed better in 5 while in 4 the prosected group performed better, in 3 studies the performance between the two groups did not differ significantly. Although the results were indefinite and most studies were stunted with methodological weaknesses, the final advantage was tilted in favor of traditional dissection when taking into account the presumed bias towards the newly introduced prosection based courses. However, in our case the results were contrary to expectations as all authors expected the 
dissection group to fare better given the higher amount of time allocated in the dissection based curriculum. The above review also highlights common errors that have prevented definite conclusions being drawn from these studies. We feel it prudent to see how we fared against the common methodological deficiencies that have marred previous studies that have compared prosections and dissections.

A more comprehensive assessment would have included practical stations with "tag tests" that could give a better reflection of the student's visual and spatial knowledge. The authors felt it unfair to subject the students to such an assessment at this point of their medical curriculum purely for research purposes. The questions on diagram identification were included in order to compensate for this deficit in the assessment tool used. The multiple choice questions were of the true/ false type where students were penalized for a wrong response with a negative mark. Although there is sufficient evidence to state that the, "best of five" type questions are a better assessment tool and while most of the assessments in the students curriculum had graduated to "best of five" type questions, we persisted with the true/false type questions as this was the question type that was used in their anatomy assessment during the first year in these student groups.

We used non randomized groups thus making this a quasi experimental study and therefore were unable to completely eliminate the effect of confounding variables between the two groups such as intelligence, visuospatial ability, time spent on self study, instruction time, the use of text books and other learning material. But we were able to control to a great extent variables such as, the number and quality of lectures, student: teacher ratios and pre knowledge which have been observed in other studies.

It is fair to presume that medical students represent a highly motivated and a selected group of high performers and they possess the ability to compensate to any intervention through their inherent abilities, thus we felt any comparison between learning methods in cadaver based learning should be done through a separate assessment preferably unannounced and more importantly away from any assessment which is part of the regular curriculum.

Finally, two very important observations need mentioning. An important advantage the new curriculum brought with it was a reduction in the amount of time spent in the dissection halls. It reduced the time spent in the dissection hall from a staggering 375 hours in the dissections group to 54 hours in the prosected group. (Table 1)

The reason for this difference in hours was due to the fact that the students were relieved of the laborious task of dissecting through fat and fascia to discover important anatomical structures and relations. This task was tackled by the anatomy demonstrators while specific times and targets were given to the students to cover each section using prosections. Thus, the time saved, could have very well been put to use in the self study of anatomy as well as of other basic sciences such as physiology and biochemistry. The additional time saved could also be used to include more curriculum content in fields such as molecular medicine and genetics which are basic sciences that are expanding daily. Thus, the results of this study could be attributed to the more structured nature of the prosections curriculum that let the 
students go about their learning in a more organized and time efficient manner. Kooloos et al (2010) demonstrated a similar advantage in long term recall when the anatomy education was strictly guided and station based.

The other important aspect to be considered in a dissection based curriculum is the proportion of students who actually engage in cadaver based self dissection. Increasing numbers in medical school admissions coupled with dwindling numbers in cadaveric donations equal to an unfavorable student to cadaver ratio. In this study the dissected group had 8-9 students allocated to one cadaver. This invariably meant that while two or three students took the task of dissecting the cadaver the remaining students engaged in learning from the prosected cadaver or self or group learning activities by the side of the dissection table. Thus, a majority of students actually completed their basic science training without engaging in self dissection. The fact that although the name implies such, a dissection based course may not be a uniform experience for all the students is an important factor that needs to be borne in mind by all investigators that try to compare dissections with other teaching methods (Winkelmann et al,2007). Similarly, the time devoted to dissections by each student has been shown to decline towards the end of each semester indicating that it is not a uniform experience for each individual either (Winkelmann et $\mathrm{al}, 2007)$. It is thus we feel the structure of the dissection based curriculum and how it is applied in the given circumstance becomes the deciding factor on the student's performance. A good balance can be achieved by combining student dissection with facilitated learning using prosections. As shown by Dinsmore et al (1999). This can be easily achieved by alternating the two learning methods between student groups on a roster basis, as have been successfully implemented in certain medical schools.

On the flip side of it one may argue that dissecting through tissue planes is a fundamental exercise in the deep learning process and a skill that will also be invaluable as surgeons. The other disadvantage in using prosections is the loss of superficial anatomical relations and surface landmarks. But this problem can be easily overcome by having prosections at different stages of dissections available for students. By allowing students to dissect it automatically allows students to use prosections as well thus allowing each student to cultivate their own study method.

Anatomy teaching is a far too important a subject to be decided by individual whims and fancies. Any change in how anatomy is taught has to be based on robust evidence and not mere personal reflection. And any change that is introduced should be followed up with continuous evaluation for its effectiveness and students performance. Learning from human cadavers is a complex experience that is difficult to measure objectively. As those who have come before us, we too suffer from confounding factors that make it difficult to arrive at concrete conclusions. Despite these shortcomings we feel that this study on its own adds to the thin body of evidence that exists to compare the two methods of cadaver based gross anatomy learning.

\section{Conclusions}


Therefore, it was concluded that a prosection based curriculum when compared to a dissection based curriculum was equally effective at establishing a core of gross anatomy knowledge in a considerably lesser amount of time.

\section{Declarations}

Ethics approval and consent to participate: All methods in this study were performed in accordance with the Declaration of Helsinki. Ethical clearance was obtained from the Ethics Review Committee of Faculty of Medicine, University of Colombo. Informed written consent was obtained from all the participants of this study.

Consent for publication: Not applicable

Availability of data and materials: All data generated or analyzed during this study are included in this published article.

Competing interests: The authors declare that they have no competing interests.

Funding: No funding

Authors' contributions: All authors equally contributed in the whole process until preparation of final manuscript. All authors read and approved the final manuscript.

Acknowledgements: Not applicable

\section{References}

1. Custers EJ. 2010. Long term retention of basic science knowledge: A review study. Adv Health Sci Educ Theory Pract 15:109-128.

2. Dinsmore CE, Daugherty S, Zeitz HJ. 1999. Teaching and learning gross anatomy: Dissection, prosection, or "both of the above?". Clin Anat 12: 110-114.

3. Gupta Y, Morgan M, Singh A, Ellis H. 2008. Junior doctors' knowledge of applied clinical anatomy. Clin Anat 21:334-338.

4. Heylings DJA. 2002. Anatomy 1999-2000: the curriculum, who teaches it and how? Med Educ36:702-710.

5. Jones DG. 1997.Reassessing the importance of dissection: A critique and elaboration. Clin Anat 10: $123-127$.

6. Kooloos JGM, de Waal Malefijt MC, Ruiter DJ,Vorstenbosch MATM. 2012, Loosely-guided, selfdirected learning versus strictly-guided, station-based learning in gross anatomy laboratory sessions. Anat Sci Educ 5: 340-346. 
7. Nnodim J0.1990. Learning human anatomy: by dissection or from prosections?Med Educ 24:389395.

8. Nnodim JO, Ohanaka EC, Osuji CU. 1996. A follow-up comparative study of two modes of learning human anatomy: By dissection and from prosections. Clin Anat9:258-262.

9. Romanes GJ. 2000a. Cunningham's manual of practical anatomy. $15^{\text {th }}$ Edition. Vol. I, Upper and lower limbs. Oxford, Oxford university press.263p

10. Romanes GJ. 2000b. Cunningham's manual of practical anatomy. $15^{\text {th }}$ Edition. Vol. II, Thorax and abdomen. Oxford, Oxford university press.298p

11. Romanes GJ. 2000c. Cunningham's manual of practical anatomy. $15^{\text {th }}$ Edition. Vol. III, Head and neck and brain. Oxford, Oxford university press.346p

12. Sugand K, Abrahams P, Khurana A. 2010. The anatomy of anatomy: A review for its modernization. Anat Sci Educ3:83-93.

13. Older J. 2004. Anatomy: A must for teaching the next generation. The Surgeon 2: 79-90

14. Winkelmann A. 2007. Anatomical dissection as a teaching method in medical school: a review of the evidence. Med Educ 41: 15-22.

15. Winkelmann A, Hendrix S, Kiessling C. 2007. What do students actually doduring a dissection course? First steps towards understanding a complex learningexperience. Acad Med 82:989-995.

\section{Figures}




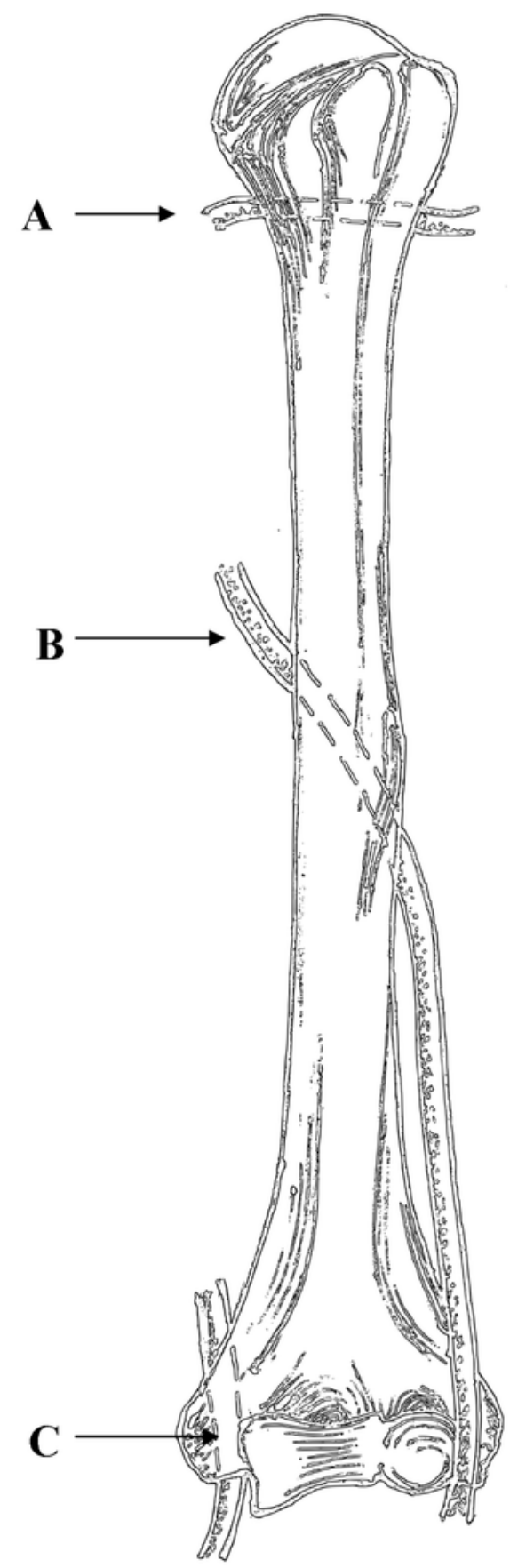

Figure 1. Identify structures A,B,C

\section{Figure 1}

See image above for figure legend. 